RESPIRATORY INFECTION

\title{
Improved survival for HIV infected patients with severe Pneumocystis jirovecii pneumonia is independent of highly active antiretroviral therapy
}

\author{
R F Miller, E Allen, A Copas, M Singer, S G Edwards
}

See end of article for authors' affiliations

Correspondence to: Professor R F Miller, Centre for Sexual Health and HIV Research, University College London, Mortimer Market Centre, London WC1E 6AU, UK; rmiller@ gum.ucl.ac.uk

Received

15 November 2005

Accepted 16 March 2006

Published Online First

6 April 2006
Background: Despite a decline in incidence of Pneumocystis jirovecii pneumonia (PCP), severe PCP continues to be a common cause of admission to the intensive care unit (ICU) where mortality remains high. A study was undertaken to examine the outcome from intensive care for patients with PCP and to identify prognostic factors.

Methods: A retrospective cohort study was conducted of HIV infected adults admitted to a university affiliated hospital ICU between November 1990 and October 2005. Case note review collected information on demographic variables, use of prophylaxis and highly active antiretroviral therapy (HAART), and hospital course. The main outcome was 1 month mortality, either on the ICU or in hospital. Results: Fifty nine patients were admitted to the ICU on 60 occasions. Thirty four patients $(57 \%)$ required mechanical ventilation. Overall mortality was 53\%. No patient received HAART before or during ICU admission. Multivariate analysis showed that the factors associated with mortality were the year of diagnosis (before mid 1996 (mortality 71\%) compared with later (mortality 34\%; $p=0.008$ )), age $(p=0.016)$, and the need for mechanical ventilation and/or development of pneumothorax $(p=0.031)$. Mortality was not associated with sex, ethnicity, prior receipt of sulpha prophylaxis, haemoglobin, serum albumin, $\mathrm{CD} 4$ count, $\mathrm{PaO}_{2}, \mathrm{~A}-\mathrm{aO}_{2}$ gradient, co-pathology in bronchoscopic lavage fluid, medical comorbidity, APACHE II score, or duration of mechanical ventilation.

Conclusions: Observed improved outcomes from severe PCP for patients admitted to the ICU occurred in the absence of intervention with HAART and probably reflect general improvements in ICU management of respiratory failure and ARDS rather than improvements in the management of PCP.
$\mathrm{P}$ neumocystis jirovecii pneumonia (PCP) continues to be a common opportunistic infection in individuals with HIV infection, ${ }^{1}$ and it remains a common indication for admission to the intensive care unit (ICU). Several studies have shown that between one quarter and one third of all ICU admissions of HIV infected patients are due to PCP. ${ }^{2-4}$ Outcomes from mechanical ventilation for severe PCP have changed dramatically since the start of the AIDS pandemic. Before 1989 reports indicated that hospital survival rates were $<20 \% .^{5-9}$ Based on this information many centres, including our own, did not refer HIV infected patients with severe PCP and respiratory failure to the ICU for mechanical ventilation. Later reports, in the late 1980s and early 1990s, showed hospital survival rates were higher, ranging from $40 \%$ to $54 \% .{ }^{10-12}$ This improvement was ascribed to the use of adjunctive corticosteroids in severe PCP..$^{10}{ }^{12} 13$ In the mid to late 1990s further reports suggested survival of patients with PCP and respiratory failure had not improved and was $<25 \%$, reflecting a poor outcome in patients who had "failed" adjuvant corticosteroids and who were admitted to the ICU $\geqslant 5$ days after starting specific anti-Pneumocystis treatment. ${ }^{912-17}$

Several factors associated with poor outcome from PCP have been identified including age of the patient, ${ }^{18}{ }^{19}$ poor oxygenation at admission to hospital (based on $\mathrm{PaO}_{2}$, or alveolar-arterial $\mathrm{O}_{2} \quad\left(\mathrm{~A}-\mathrm{aO}_{2}\right)$ gradient $),{ }^{70-22}$ raised serum lactate dehydrogenase (LDH) enzyme levels, ${ }^{20} 2123$ low haemoglobin, ${ }^{19} 24$ low serum albumin, ${ }^{42025}$ the presence of bacterial $^{21}$ or cytomegalovirus $(\mathrm{CMV})^{18}$ co-pathogens or neutrophilia in bronchoalveolar lavage (BAL) fluid, ${ }^{26}$ delay of $\geqslant 5$ days in admission to ICU after starting specific anti-Pneumocystis treatment, ${ }^{125}$ high Acute Physiology and
Chronic Health Evaluation (APACHE) II scores, ${ }^{3} 25$ and development of pneumothorax during mechanical ventilation. ${ }^{927}$ Results from these studies are inconsistent as not all show these factors to have prognostic value. There is no scoring system with sufficient accuracy to enable identification of individuals for whom referral to the ICU for mechanical ventilation would be futile.

One recent retrospective study from San Francisco General Hospital demonstrated improved survival from HIV associated PCP in patients who either began highly active antiretroviral therapy (HAART) while on the ICU or who were receiving HAART before admission to the ICU (survival $63 \%$ ) compared with those who did not receive HAART (survival 25\%). ${ }^{28}$ By contrast, acute deterioration has been described when HAART is commenced during treatment of severe PCP..$^{29}$ At our treatment centre HAART is not started during treatment of acute intercurrent opportunistic infections, but our perception is that outcomes have steadily been improving in this patient group. We therefore performed a retrospective study of all HIV infected patients with PCP admitted to our ICU from 1990 to the present in order to document trends in outcome and survival and to identify prognostic factors associated with death.

\section{METHODS}

\section{Patients}

Consecutive HIV infected adults admitted to the ICU at University College London Hospitals (UCLH) from November

Abbreviations: BAL, bronchoalveolar lavage; HAART, highly active antiretroviral therapy; $\mathrm{LDH}$, lactate dehydrogenase; $\mathrm{PaO}_{2}$, arterial oxygen tension; PCP, Pneumocystis jirovecii pneumonia 
1990 until October 2005 were identified. Before this time, HIV infected patients with severe PCP were not admitted to the ICU; instead, they were managed on a specialist HIV/ AIDS ward and were given respiratory support with continuous positive airways pressure (CPAP) delivered via a face mask. ${ }^{31}$ All patients had microscopically confirmed PCP. $^{32}$ In 56 episodes PCP was diagnosed by bronchoscopy with BAL and four episodes were diagnosed at necropsy. Each patient had one ICU admission, apart from one woman who had two admissions in 1993 and 1995, the second of which led to death. Patients in whom the diagnosis of PCP was made empirically ${ }^{33}$ were excluded from the main part of the study, but limited information was collected for comparison purposes. Patients were identified from a manual and electronic search of hospital discharge summaries of HIV infected patients and cross referenced with the electronic ICU database and with the pathology department records.

UCLH is a 936 bed university affiliated teaching hospital that provides inpatient care for HIV infected patients: there are 22 general ICU beds. The study was carried out with the approval of the University College London Hospitals research ethics committee. The size of the study was not based on a power calculation.

\section{Data collection}

Demographic information recorded included age, sex, ethnicity, and risk factor for HIV acquisition, patients' awareness of their HIV serostatus at admission, previous history of PCP, and receipt of PCP prophylaxis. The admission $\mathrm{PaO}_{2}$ (breathing room air), $\mathrm{A}-\mathrm{aO}_{2}$ gradient, haemoglobin and serum albumin, CD4 count (on or within 1 month before admission), presence of co-morbidity, and evidence of co-pathogens in BAL fluid (bacterial infection or CMV) defined as previously described ${ }^{32}{ }^{34}$ were recorded. Serum $\mathrm{LDH}$ is not routinely measured in patients with PCP at our treatment centre.

Data recorded on each patient's hospital course included treatment of PCP and whether treatment was changed because of drug failure. Treatment failure was defined as a need for a change in treatment due to persistent fever or worsening hypoxaemia, with or without radiographic deterioration, occurring after a minimum of 5 days of primary treatment (including adjuvant corticosteroids), or a lack of improvement in oxygenation, chest radiograph, or clinical symptoms after 10 days of primary treatment. ${ }^{35}{ }^{36}$ Hospital day of admission to ICU, APACHE II score ${ }^{37}$ on day of ICU admission, duration of ICU stay, need for mechanical ventilation, development of pneumothorax (and whether pneumothorax occurred during mechanical ventilation), and outcome were also recorded. Outcome was described either as death or survival 4 weeks after completing treatment for PCP. Whether death occurred on the ICU or elsewhere in the hospital was also recorded. Patients surviving the ICU admission were followed up for 3 months.

\section{Statistical analysis}

Stata Version 7.0 (StataCorp, College Station, Texas, USA) was used for statistical analysis. A p value of $<0.05$ was regarded as statistically significant. Univariate analyses were performed using a two tailed Fisher exact test for binary variables and a Mann-Whitney test for continuous variables to assess variables associated with survival. Only one patient with a pneumothorax was not mechanically ventilated, so we created a variable that accounted for both the need for mechanical ventilation and/or development of pneumothorax. Stepwise forward multivariate logistic regression was performed in order to determine variables (factors) predictive of poor outcome. The two episodes from one

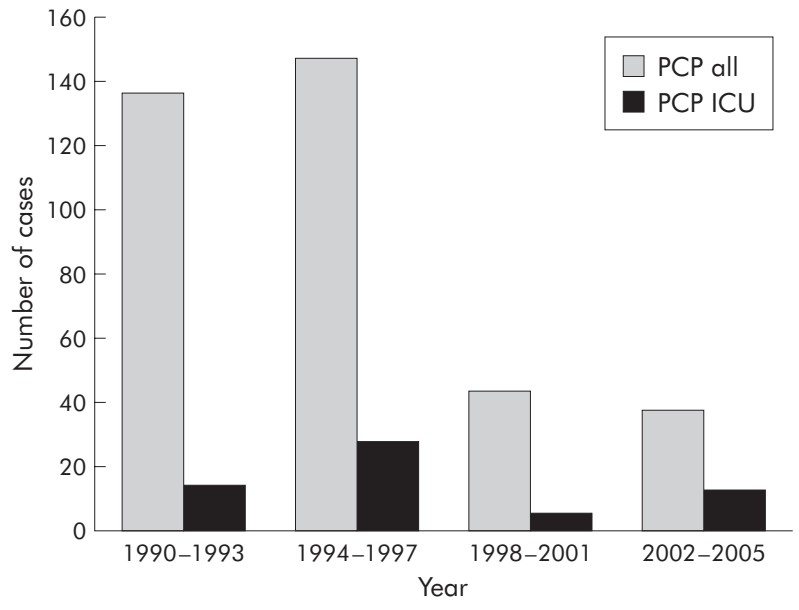

Figure 1 Number of cases of microscopically confirmed Pneumocystis jirovecii pneumonia (PCP) diagnosed at University College London Hospitals by year and number of cases of microscopically confirmed PCP who were admitted to the ICU.

patient are treated in the analysis as independent. Data presented are based on episodes.

\section{RESULTS}

Fifty nine HIV infected patients were admitted to the ICU with severe PCP on 60 occasions between November 1990 and October 2005. Overall mortality was 53\%. Mortality before mid 1996 was $71 \%$ and thereafter was 34\%. During this time period 328 patients had 367 episodes of microscopically confirmed PCP at this centre. A significantly higher proportion of patients with PCP were admitted to the ICU in the period 2002-5 than in the rest of the study period (13/38 $(43 \%) v 47 / 329$ (14\%), $\mathrm{p}=0.003$, fig 1 ).

Patients admitted to the ICU were predominantly men (87\%); their main HIV risk factor was sex with other men (MSM) (67\%) and their median (range) age was 36.5 (2368 ) years (table 1). A comparison of patients with PCP before mid $1996(\mathrm{n}=31)$ with those presenting after this time $(n=29)$ showed that they were of similar age (median (range) $41 \quad(23-68) \quad v \quad 35$ (26-68) years, $p=0.66)$. The majority were male (94\% (29/31) before mid 1996 v 79\% $(23 / 29)$ subsequently, $p=0.14)$. Patients were more likely to be MSM before mid 1996 than later (24/31 (84\%) $v$ 14/29 $(48 \%), p=0.006)$.

Admission with PCP in the 59 patients represented the initial HIV diagnosis for 35 patients (58\%). None were receiving HAART on admission to hospital and none began HAART treatment while in the ICU; 51 (85\%) were not receiving PCP prophylaxis before hospital admission. Patients generally had advanced HIV disease with a median (range) CD4 count of $30(0-320)$ cells/ $\mu l$. All but three patients had CD4 counts of $\leqslant 200$ cells/ $\mu$ l. In 57 episodes $(95 \%)$ this was the first episode of PCP; in three (5\%) it was the second episode. Thirty four patients required mechanical ventilation (57\%) and 12 developed a pneumothorax; in 11 (92\%) of these pneumothorax occurred while being mechanically ventilated. Twenty six patients (43\%) did not require mechanical ventilation and instead received respiratory support including CPAP.

Primary treatment was co-trimoxazole in 56 episodes (93\%), clindamycin with primaquine in three $(5 \%)$, and intravenous pentamidine in one (2\%); $56(93 \%)$ also received adjuvant corticosteroids. At the time of admission to the ICU six $(10 \%)$ patients were already receiving second line therapy due to failure of first line treatment. Co-pathology was 
Table 1 Characteristics of 60 episodes of microbiologically confirmed PCP admitted to the intensive care unit according to survival

\begin{tabular}{|c|c|c|c|c|}
\hline Characteristic & $\begin{array}{l}\text { Survivors } \\
(\mathrm{N}=28)\end{array}$ & $\begin{array}{l}\text { Non-survivors } \\
(\mathrm{N}=32)\end{array}$ & $\begin{array}{l}\text { Overall } \\
(\mathrm{N}=60)\end{array}$ & $\mathrm{p}$ value \\
\hline \multicolumn{5}{|l|}{ Sex } \\
\hline Men & $23(82 \%)$ & $29(91 \%)$ & $52(87 \%)$ & \multirow{2}{*}{0.454} \\
\hline Women & $5(8 \%)$ & $2(9 \%)$ & $8(13 \%)$ & \\
\hline \multicolumn{5}{|l|}{ Race/ethnicity } \\
\hline White & $24(86 \%)$ & $22(69 \%)$ & $46(77 \%)$ & \multirow{2}{*}{0.214} \\
\hline Other & $4(14 \%)$ & $10(31 \%)$ & $14(23 \%)$ & \\
\hline \multicolumn{5}{|l|}{ Year of diagnosis } \\
\hline Before mid 1996 & $9(32 \%)$ & $22(69 \%)$ & $31(52 \%)$ & \multirow[t]{2}{*}{0.009} \\
\hline After mid 1996 & $19(68 \%)$ & $10(31 \%)$ & $29(48 \%)$ & \\
\hline \multicolumn{5}{|l|}{ HIV risk factor } \\
\hline Men who have sex with men & $18(64 \%)$ & $22(69 \%)$ & $40(67 \%)$ & \multirow[t]{2}{*}{0.787} \\
\hline Heterosexual & $10(36 \%)$ & $10(31 \%)$ & $20(33 \%)$ & \\
\hline \multicolumn{5}{|l|}{$\begin{array}{l}\text { Known to be HIV infected before presentation } \\
\text { with PCP }\end{array}$} \\
\hline Yes & $8(29 \%)$ & $17(53 \%)$ & $25(42 \%)$ & \multirow[t]{2}{*}{0.069} \\
\hline No & 20 (71\%) & $15(47 \%)$ & $35(58 \%)$ & \\
\hline Age (years)† & $32.5(23-60)$ & $41.5(25-68)$ & $36.5(23-68)$ & 0.025 \\
\hline \multicolumn{5}{|l|}{ Prior history of PCP } \\
\hline Yes & $0(0 \%)$ & $3(9 \%)$ & $3(5 \%)$ & \multirow{2}{*}{0.241} \\
\hline No & $28(100 \%)$ & $29(91 \%)$ & $57(95 \%)$ & \\
\hline \multicolumn{5}{|l|}{ Receipt of PCP prophylaxis } \\
\hline Yes & $2(7 \%)$ & $7(22 \%)$ & $9(15 \%)$ & \multirow{2}{*}{0.155} \\
\hline No & $26(93 \%)$ & $25(78 \%)$ & $57(95 \%)$ & \\
\hline \multicolumn{5}{|l|}{ Laboratory results } \\
\hline CD4 cells $\left(\times 10^{6} / \mathrm{l}\right) \dagger$ & $35(0-320)$ & $30(0-100)$ & $30(0-320)$ & 0.515 \\
\hline Admission $\mathrm{PaO}_{2}$ breathing room air $(\mathrm{kPa}) \dagger$ & $7.0(4.0-13.6)$ & $7.8(3.9-11.3)$ & $7.6(3.9-13.6)$ & 0.583 \\
\hline Admission $\mathrm{A}-\mathrm{aO}_{2}$ gradient $(\mathrm{kPa}) \dagger$ & $7.4(1.6-10.8)$ & $7.3(2.4-10.6)$ & $7.3(1.6-10.6)$ & 0.699 \\
\hline Haemoglobin $(\mathrm{g} / \mathrm{d}$ ) $) \ddagger$ & $11.4(1.87)$ & $10.8(1.49)$ & $11.1(1.69)$ & 0.176 \\
\hline Serum albumin $(\mathrm{g} / \mathrm{l}) \ddagger$ & $27.4(5.97)$ & $24.6(5.42)$ & $26.0(5.81)$ & 0.071 \\
\hline APACHE II scoref & $15.1(4.08)$ & $16.1(6.52)$ & $15.6(5.49)$ & 0.522 \\
\hline Complications & & & & \\
\hline Admission to ICU & & & & \\
\hline$\leqslant 5$ days after hospital admission & $17(61 \%)$ & 19 (59\%) & $36(60 \%)$ & 0.563 \\
\hline$>5$ days after hospital admission & $11(39 \%)$ & $13(41 \%)$ & $24(40 \%)$ & \\
\hline Treatment failure at admission to ICU & & & & \\
\hline Yes & $2(7 \%)$ & $4(13 \%)$ & $6(10 \%)$ & 0.678 \\
\hline No & $25(93 \%)$ & $28(87 \%)$ & $54(90 \%)$ & \\
\hline Medical co-morbidity & & & & \\
\hline Yes & $3(11 \%)$ & $9(28 \%)$ & $12(20 \%)$ & 0.115 \\
\hline No & $25(89 \%)$ & $23(72 \%)$ & $48(80 \%)$ & \\
\hline CMV infection in BAL fluid & & & & \\
\hline Yes & $3(11 \%)$ & $3(9 \%)$ & $6(11 \%)$ & 1.00 \\
\hline No & $25(89 \%)$ & $25(91 \%)^{*}$ & $50(89 \%)$ & \\
\hline Bacterial infection in BAL fluid & & & & \\
\hline Yes & $3(11 \%)$ & $4(14 \%)$ & 7 (12\%) & 1.00 \\
\hline No & $25(89 \%)$ & $24(86 \%)^{*}$ & $49(88 \%)$ & \\
\hline $\begin{array}{l}\text { Medical co-morbidity, CMV or bacterial infecti } \\
\text { in BAL fluid }\end{array}$ & & & & \\
\hline Yes & $9(32 \%)$ & $14(44 \%)$ & $23(38 \%)$ & 0.430 \\
\hline No & $19(68 \%)$ & $18(56 \%)$ & $37(62 \%)$ & \\
\hline Mechanical ventilation & & & & \\
\hline Yes & $12(43 \%)$ & $22(69 \%)$ & $34(57 \%)$ & 0.067 \\
\hline No & $16(57 \%)$ & $10(31 \%)$ & $26(43 \%)$ & \\
\hline Duration of mechanical ventilation (days) $\dagger$ & $8(1-28)$ & $11.5(1-75)$ & $9.5(1-75)$ & 0.539 \\
\hline Pneumothorax & & & & \\
\hline Yes & $4(14 \%)$ & $8(25 \%)$ & $12(20 \%)$ & 0.349 \\
\hline No & $24(86 \%)$ & $24(75 \%)$ & $48(80 \%)$ & \\
\hline Mechanical ventilation and/or pneumothorax & & & & \\
\hline Yes & $12(43 \%)$ & $23(72 \%)$ & $35(58 \%)$ & 0.036 \\
\hline No & $16(57 \%)$ & $9(28 \%)$ & $25(42 \%)$ & \\
\hline Survival & & & & \\
\hline Died in ICU & $0(0 \%)$ & $26(81 \%)$ & $26(43 \%)$ & NA \\
\hline Died in hospital & $0(0 \%)$ & $6(19 \%)$ & $6(10 \%)$ & \\
\hline Survived to hospital discharge & $28(100 \%)$ & $0(0 \%)$ & $28(47 \%)$ & \\
\hline
\end{tabular}

Values are shown as $n(\%)$ unless otherwise stated.

PCP, Pneumocystis jirovecii pneumonia; APACHE, Acute Physiology and Chronic Health Evaluation; ICU, intensive care unit; CMV, cyłomegalovirus; BAL, bronchoalveolar lavage fluid; NA, not applicable.

*Four patients were diagnosed at necropsy.

†Median (range).

$\ddagger$ Mean (SD).

identified in the BAL fluid of 12 patients (20\%)—Streptococcus pneumoniae $(\mathrm{n}=3)$, Staphylococcus aureus $(\mathrm{n}=2$, one also had $\mathrm{CMV})$, Pseudomonas aeruginosa $(\mathrm{n}=2)$, and CMV alone $(\mathrm{n}=5)$. Twelve patients $(20 \%)$ had co-morbidities: cryptococcal infection $(\mathrm{n}=4)$, heart failure/cardiomyopathy $(\mathrm{n}=2)$, and histoplasmosis, recent cerebrovascular accident, tuberculosis, hypothyroidism, kyphoscoliosis and acute renal failure in one patient each. Of 56 episodes of PCP diagnosed by bronchoscopy 
Table 2 Multivariate analysis of factors associated with mortality

\begin{tabular}{lll}
\hline Characteristic & Odds ratio $(95 \% \mathrm{Cl})$ & $\mathrm{p}$ value \\
\hline $\begin{array}{l}\text { Age (log* years) } \\
\text { Year of PCP diagnosis }\end{array}$ & $19.76(1.74$ to 224.34) & 0.016 \\
$\begin{array}{l}\text { (after mid 1996) } \\
\text { Mechanical ventilation } \\
\text { and/or pneumothorax }\end{array}$ & $5.18(1.16$ to 23.15) & 0.031 \\
\hline${ }^{*}$ Natural log. & & \\
\hline
\end{tabular}

and BAL, 16 patients ( $18 \%$ ) were admitted to the ICU within 24 hours of the procedure, six of whom required mechanical ventilation on admission to the ICU. Disease severity in these 16 patients as determined by $\mathrm{PaO}_{2}$ (median $\mathrm{PaO}_{2} 7.7$ (range 3.913.6) $\mathrm{kPa}$ ) was no different from the rest of the group. Overall, 32 patients (53\%) did not survive their episode of PCP; 26 died on the ICU and six died on the specialist HIV/AIDS ward following discharge from the ICU. The majority of deaths were due to progressive respiratory failure.

In univariate analysis the only factors significantly associated with mortality were the year of diagnosis of PCP (before mid $1996 v$ later), age, and the need for mechanical ventilation and/or development of pneumothorax (table 1). Sex, ethnicity, HIV risk factors, lack of awareness of HIV status, a prior history of PCP, receipt of PCP prophylaxis, haemoglobin, serum albumin and CD4 count, $\mathrm{PaO}_{2}, \mathrm{~A}-\mathrm{aO}_{2}$ gradient, co-pathology in BAL fluid, medical co-morbidity, APACHE II score, and duration of mechanical ventilation were not significantly associated with mortality. However, there was some evidence of an association with serum albumin and lack of awareness of HIV status. In multivariate analysis (table 2) the year of diagnosis of PCP, age, and the need for mechanical ventilation and/or development of pneumothorax remained significantly associated with mortality. The severity of microbiologically confirmed PCP (measured by admission $\mathrm{PaO}_{2}$ ) throughout the study period, both in those admitted to the ICU and in all those with PCP is shown in table 3. A comparison of patients presenting after mid 1996 with those presenting before this date revealed a significantly lower $\mathrm{PaO}_{2}$ in both those admitted to the ICU $(p=0.003)$ and overall $(p<0.001)$. Among survivors the median duration of ICU stay was 3 days (range 1-17) before mid 1996 and 11 days (range $1-34)$ subsequently $(\mathrm{p}=0.92)$.

When longer term survival (at 3 months) was considered, a marked decline in mortality over time was also identified. Mortality before mid 1996 was 74\% (23/31) and 38\% (11/29) subsequently $(p=0.009)$. Restricting analysis to only those who were mechanically ventilated, a reduction in 1 month mortality from $81 \%$ (13/16) before mid 1996 to 50\% (9/18) thereafter was observed. This was not statistically significant $(p=0.08)$. The rate of pneumothoraces in mechanically ventilated patients was 43\% (7/16) before mid 1996 and $28 \%(5 / 18)$ subsequently $(p=0.475)$.

Twenty four additional patients with "empirically treated" PCP were admitted to the ICU during the study period. Mortality also declined markedly over time in this group $(\mathrm{p}=0.01)$, being $91 \%(10 / 11)$ before mid 1996 and 38\% (5/ $13)$ thereafter. This overall mortality rate $(63 \%)$ was somewhat higher than in those with microscopically confirmed PCP $(53 \%, p=0.48)$.

\section{DISCUSSION}

This study demonstrates an improved survival for HIV infected patients with PCP who require admission to the ICU. Although overall mortality was 53\%, mortality rates at this treatment centre have fallen since mid 1996. Independent predictors of mortality in this study were the
Table 3 Admission oxygenation $\left(\mathrm{PaO}_{2}\right.$, breathing room air) for all patients with microbiologically confirmed PCP and for those admitted to the ICU with microbiologically confirmed PCP

\begin{tabular}{ll}
\hline Study period/patient group & $\begin{array}{c}\text { Admission } \mathrm{PaO}_{2}(\mathbf{k P a}, \\
\text { breathing room air)* }\end{array}$ \\
\hline $1990-1993$ & $7.9(3.9-13.1)$ \\
ICU PCP $(n=14)$ & $9.4(3.9-13.2)$ \\
All PCP $(n=137)$ & $7.7(4.8-13.6)$ \\
$1994-1997$ & $9.4(5.0-13.6)$ \\
ICU PCP $(n=28)$ & \\
All PCP $(n=148)$ & $6.2(4.0-10.1)$ \\
$1998-2001$ & $9.3(4.0-13.2)$ \\
ICU PCP $(n=5)$ & $6.9(5.2-8.7)$ \\
All PCP $(n=44)$ & $7.9(5.2-11.4)$ \\
$2002-2005$ & \\
ICU PCP ( $n=13)$ & \\
All PCP ( $n=38)$ & \\
\hline & Values are median (range). \\
*In a comparison of patients presenting before mid 1996 \\
and those presenting subsequently, PaO 2 was lower in those \\
admitted to the ICU ( $p=0.003)$ and overall $(p<0.001)$.
\end{tabular}

year of diagnosis of PCP, the age of the patient, and the need for mechanical ventilation and/or development of pneumothorax. In multivariate analysis these factors remained significant. Overall survival from PCP has improved during the last two decades. ${ }^{38}{ }^{39}$ Morris et al ${ }^{28}$ suggested that improved survival among HIV infected patients with severe PCP who were admitted to the ICU was related to the patient's receipt of HAART which became available in the UK in mid 1996. In our institution, mortality from severe PCP requiring admission to the ICU fell from 71\% before mid 1996 to $34 \%$ subsequently, despite the fact that no patient received HAART before or during admission to the ICU. These survival figures are similar to those reported by Morris et al..$^{28}$ In our study the observed improved survival cannot be ascribed to HAART.

Over the last decade there have been several changes in the ICU management of patients with acute lung injury (ALI) and acute respiratory distress syndrome (ARDS) which have positively impacted on survival. ${ }^{40}{ }^{41}$ In particular, the use of lower tidal volumes and higher levels of positive end expiratory pressure for mechanical ventilation are associated with better outcomes. ${ }^{40}{ }^{41}$ With these interventions survival from ARDS has improved from 41-52\% before 1991 to 60 $75 \%$ in 1993 and subsequently. ${ }^{40}{ }^{41}$ This centre's strategy for management of mechanically ventilated patients with ALI/ ARDS changed soon after publication of data from Hickling et al which showed a reduced mortality rate if low tidal volume ventilation with permissive hypercapnia was used. ${ }^{42}$ Thus, by early 1996 our centre allowed mechanically ventilated patients with ALI/ARDS to tolerate greater levels of hypoxaemia and permissive hypercapnia. Additionally, mechanically ventilated patients were less frequently paralysed and less intravenous fluid was administered to critically ill patients than previously. This suggests that the observed improvement in survival from severe PCP reflects improvements in ICU management of severe respiratory failure rather than changes in the specific management of PCP.

The introduction and uptake of HAART in mid 1996 was associated with a marked reduction in AIDS events and mortality. ${ }^{43}$ This was accompanied by a changed perception among clinicians caring for patients with HIV infection such that they were more likely to refer to the ICU patients with severe PCP, as shown by the results from the last quarter of this study where a greater proportion of patients with PCP were admitted to the ICU. Throughout the study period there 
were no changes in clinical practice, as bronchoscopy with BAL was used as the exclusive diagnostic modality and no transbronchial biopsies (with the attendant risk of pneumothorax) nor open lung biopsies were performed. First line treatment was co-trimoxazole, regardless of disease severity, and adjuvant corticosteroids had been introduced in late 1989 for those with $\mathrm{PaO}_{2}<9.3 \mathrm{kPa}$. However, among those surviving severe PCP there was a trend (which did not reach statistical significance) for the duration of ICU stay to be longer after mid 1996, perhaps reflecting treatment optimism among clinicians.

This study has two weaknesses. Firstly, only patients with microscopically confirmed PCP were included in the analysis. Those with a presumptive diagnosis and those who were treated empirically were excluded. ${ }^{33}$ Many of these latter patients were too sick to undergo bronchoscopy and may or may not have had PCP. No necropsy was performed in these patients, so uncertainty remains regarding their diagnosis. Secondly, the study population was small and is not based on a power calculation, yet is comparable in size to most of the studies of PCP in the ICU between 1981 and 2003 which have previously identified factors with prognostic significance. $^{3} 4791214-27$ Nevertheless, interpretation of associations which are not statistically significant requires caution.

The suggestion that the observed improved prognosis in this study results from patients being more likely to be younger in recent years, to present with milder disease, and with a previous diagnosis of HIV is not supported by the study findings. No differences were seen over time in the age of patients, prior knowledge of their HIV serostatus, CD4 count and haemoglobin (both surrogates of advanced HIV infection), or median $\mathrm{PaO}_{2}$ at presentation. Throughout the study most of the patients presented with late stage HIV infection and PCP as their AIDS defining events. These data contrast with previous reports which have found that these prognostic factors are associated with death from PCP. ${ }^{3} 79^{12-27}$ Two previous studies showed that the patient's prior receipt of PCP prophylaxis was associated with a poor outcome from severe PCP ${ }^{44} 45$ which was ascribed to acquired co-trimoxazole resistance. ${ }^{45}$ By contrast, we were unable to demonstrate an association between patient's prior receipt of sulpha prophylaxis and death, although only nine patients (15\%) had received co-trimoxazole before presentation with PCP.

We identified no difference in outcome from severe PCP, regardless of the duration of specific treatment before admission to the ICU, as reported previously. ${ }^{44}$ These data contrast with other reports which hypothesised that, if a patient deteriorated within 5 days of starting antiPneumocystis treatment deterioration was occurring before adjuvant corticosteroids had become effective whereas, if deterioration occurred $\geqslant 5$ days after starting treatment, patients in whom adjunctive corticosteroids had not worked and who were deteriorating despite maximal treatment had been selected. ${ }^{525}$ Our data suggest that referral to the ICU for management of severe PCP is appropriate even in patients deteriorating after $>5$ days of maximal treatment. In contrast to the study by El Sadr and Simberkoff ${ }^{7}$ which found better ICU outcomes for patients with PCP who deteriorated immediately after bronchoscopy and BAL, in the present study 16 patients ( $18 \%$ ) admitted to the ICU within 24 hours of BAL had similar outcomes and showed no differences in $\mathrm{PaO}_{2}$ compared with the group as a whole.

The data from this study show improved survival from severe PCP in recent years in the context of the advent of HAART, and support early referral to the ICU of patients with severe PCP for management of respiratory failure. We failed to identify specific factors associated with a poor outcome such as patients failing first line treatment or a prolonged interval between hospitalisation and ICU admission which would preclude referral to the ICU for management. The observed improvements in outcome from the ICU for patients with severe PCP occurred in the absence of intervention with HAART, and probably reflect general improvements in ICU management of respiratory failure and ARDS rather than improvements in the management of PCP per se.

\section{Authors' affiliations}

R F Miller, E Allen, A Copas, Centre for Sexual Health and HIV Research, Department of Primary Care and Population Sciences, Royal Free and University College Medical School, University College London, London, UK

M Singer, Bloomsbury Institute of Intensive Care Medicine, Royal Free and University College Medical School, University College London, London, UK

S G Edwards, Department of Genitourinary Medicine, Camden PCT, London, UK

Funding: none.

Conflict of interest: Professor RF Miller is Co-Editor and Dr A Copas is Associate Editor of Sexually Transmitted Infections, part of the BMJ Publishing Group.

\section{REFERENCES}

1 Morris A, Lundgren JD, Masur $\mathrm{H}$, et al. Current epidemiology of Pneumocystis pneumonia. Emerg Infect Dis 2004;10:1713-20.

2 Gill JK, Greene L, Miller R, et al. ICU admission in patients infected with the human immunodeficiency virus: a multicentre survey. Anaesthesia 1999;54:727-32.

3 Afessa B, Green B. Clinical course, prognostic factors, and outcome prediction for HIV patients in the ICU. The PIP (Pulmonary complications, ICU support, and Prognostic factors in hospitalized patients with HIV) study. Chest 2000; 1 18:138-45.

4 Alves C, Nicolás JM, Miró JM, et al. Reappraisal of the aetiology and prognostic factors of severe acute respiratory failure in HIV patients. Eur Respir J 2001;17:87-93.

5 Murray JF, Felton CP, Garay SM, et al. Pulmonary complications of the acquired immunodeficiency syndrome. Report of a Nation Heart, Lung, and Blood Institute workshop. N Engl J Med 1984;310:1682-8.

6 Schein MH, Fischl MA, Pitchenik AE, et al. ICU survival of patients with the acquired immunodeficiency syndrome. Crit Care Med 1986;14:1026-7.

7 El Sadr W, Simberkoff MS. Survival and prognostic factors in severe PCP requiring mechanical ventilation. Am Rev Respir Dis 1988;137:1264-7.

8 Smith RL, Levine SM, Lewis ML. Prognosis of patients with AIDS requiring intensive care. Chest 1989;96:557-61.

9 Wachter RM, Luce JM, Safrin S, et al. Cost and outcome of intensive care for patients with AIDS, Pneumocystis carinii pneumonia, and severe respiratory failure. JAMA 1995;273:230-5.

10 Friedman $Y$, Franklin C, Rackow EC, et al. Improved survival in patients with AIDS, Pneumocystis carinii pneumonia, and severe respiratory failure. Chest 1989;96:862-6.

11 Montaner JS, Hawley PH, Ronco JJ, et al. Multisystem organ failure predicts mortality of ICU patients with acute respiratory failure secondary to AIDSrelated PCP. Chest 1992;102:1823-8.

12 Staikowsky F, Lafon B, Guidet B, et al. Mechanical ventilation for Pneumocystis carinii pneumonia in patients with the acquired immunodeficiency syndrome. Is the prognosis really improved? Chest 1993;104:756-62

13 Montaner JSG, Russell JA, Lawson L, et al. Acute respiratory failure secondary to Pneumocystis carinii pneumonia in the acquired immunodeficiency syndrome. Chest 1989;95:881-4.

14 De Palo VA, Millstein BH, Mayo PH, et al. Outcome of intensive care in patients with HIV infection. Chest 1995;107:506-10.

15 Hawley PH, Ronco JJ, Guillemi SA, et al. Decreasing frequency but worsening mortality of acute respiratory failure secondary to AIDS-related Pneumocystis carinii pneumonia. Chest 1994;106:1456-9.

16 Kumar SD, Krieger BP. CD4 lymphocyte counts and mortality in AIDS patients requiring mechanical ventilator support due to Pneumocystis carinii pneumonia. Chest 1998;113:430-3.

17 Bennett RL, Gilman SC, George L, et al. Improved outcomes in intensive care units for AIDS-related Pneumocystis carinii pneumonia: 1987-1991. J Acquir Immune Defic Syndr 1993;6:1319-21.

18 Benfield TL, Helweg-Larsen J, Bang D, et al. Prognostic markers of short-term mortality in AIDS-associated Pneumocystis carinii pneumonia. Chest $2001 ; 119: 844-51$

19 Matthews WC, Ferdon E, Bennett CL, et al. Evaluating institutional performance in AIDS-associated Pneumocystis carinii pneumonia: a risk adjustment approach. J Clin Epidemiol 1989;42:421-5.

20 Kales CP, Murren JR, Torres RA, et al. Early predictors of in-hospital mortality for Pneumocystis carinii pneumonia in the acquired immunodeficiency syndrome. Arch Intern Med 1987; 14:1413-7. 
21 Benson C, Spear J, Hines D, et al. Combined APACHE II score and serum lactate dehydrogenase as predictors of in-hospital mortality caused by first episode Pneumocystis carinii pneumonia in patients with acquired immunodeficiency syndrome. Am Rev Respir Dis 1991;144:319-23.

22 Brenner M, Ognibene FP, Lack E, et al. Prognostic factors and life expectancy of patients with acquired immunodeficiency syndrome and Pneumocystis carinii pneumonia. Am Rev Respir Dis 1987;136:1199-206.

23 Lipman ML, Goldstein E. Serum lactate dehydrogenase predicts mortality in patients with AIDS and Pneumocystis pneumonia. West J Med 1988;149:486-7.

24 Baver T, Ewig S, Hasper E, et al. Predicting in-hospital outcome in HIVassociated Pneumocystis carinii pneumonia. Infection 1995;23:272-7.

25 Forrest DM, Zala C, Djurdjev O, et al. Determinants of short-and long-term outcome in patients with respiratory failure caused by AIDS-related Pneumocystis carinii pneumonia. Arch Intern Med 1999;159:741-7.

26 Mason GR, Hashimoto CH, Dickman PS, et al. Prognostic implications of bronchoalveolar lavage neutrophilia in patients with Pneumocystis carinii pneumonia and AIDS. Am Rev Respir Dis 1989;139:1336-42.

27 Bedos J-P, Dumulin J-L, Gachot B, et al. Pneumocystis carinii pneumonia requiring intensive care management: survival and prognostic study in 110 patients with human immunodeficiency virus. Crit Care Med 1999;27:1109-15.

28 Morris A, Wachter RM, Luce J, et al. Improved survival with highly active antiretroviral therapy in HIV-infected patients with severe Pneumocystis carinii pneumonia. AIDS 2003;17:73-80.

29 Wislez $M$, Bergot $E$, Antoine $M$, et al. Acute respiratory failure following HAART introduction in patients treated for Pneumocystis carinii pneumonia. Am J Respir Crit Care Med 2001;164:847-51.

30 Dean GL, Williams DI, Churchill DR, et al. Transient clinical deterioration in HIV patients with Pneumocystis carinii pneumonia after starting highly active antiretroviral therapy: another case of immune restoration inflammatory syndrome. Am J Respir Crit Care Med 2002; 165:1670.

31 Miller RF, Semple SJG. Continuous positive airways pressure ventilation for respiratory failure associated with Pneumocystis carinii pneumonia. Respir Med 1991;85:133-8.

32 Miller RF, Kocjan G, Buckland J, et al. Sputum induction for the diagnosis of respiratory disease in HIV positive patients. J Infect 1991;23:5-16.

33 Miller RF, Millar AB, Weller IVD, et al. Empirical therapy without bronchoscopy for Pneumocystis carinii pneumonia in the acquired immunodeficiency syndrome. Thorax 1989;44:559-64.
34 Wakefield AE, Lindley AL, Ambrose HE, et al. Limited asymptomatic carriage of Pneumocystis jiroveci in human immunodeficiency virus-infected patients. $J$ Infect Dis 2003;187:901-8.

35 Wharton JM, Coleman DL, Wofsy CB, et al. Trimethoprim-sulfamethoxazole or pentamidine for Pneumocystis carinii pneumonia in the acquired immunodeficiency syndrome. A prospective randomized trial. Ann Intern Med 1986;105:37-44.

36 Sattler FR, Cowan R, Nielsen DM, et al. Trimethoprim-sulfamethoxazole compared with pentamidine for treatment of Pneumocystis carinii pneumonia in the acquired immunodeficiency syndrome: a prospective, non-crossover study. Ann Intern Med 1988;109:280-7.

37 Knaus WA, Draper EA, Wagner DP, et al. APACHE II: a severity of disease classification system. Crit Care Med 1985;13:818-29.

38 Lundgren JD, Barton SE, Katlama C, et al. Changes in survival over time after a first episode of Pneumocystis carinii pneumonia for European patients with acquired immunodeficiency syndrome. Multicentre Study Group on AIDS in Europe. Arch Intern Med 1995; 155:822-88.

39 Colford JM, Segal M, Tabnak F, et al. Temporal trends and factors associated with survival after Pneumocystis carinii pneumonia in California, 1983-1992. Am J Epidemiol 1997;146:115-27.

40 Petrucci N, Ivacovelli W. Ventilation with lower tidal volumes versus traditional tidal volumes in adults for acute lung injury and acute respiratory distress syndrome. Cochrane Database Syst Rev 2003;(3):CD003844.

41 Bernard GR. Acute respiratory distress syndrome. A historical perspective. Am J Respir Crit Care Med 2005;172:798-806.

42 Hickling KG, Walsh J, Henderson S, et al. Low mortality rate in adult respiratory distress syndrome using low-volume, pressure-limited ventilation with permissive hypercapnia: a prospective study. Crit Care Med 1994;22:1568-78.

43 Palella FJ, Delaney KM, Moorman AC, et al. Declining morbidity and mortality among patients with advanced human immunodeficiency virus infection. HIV Outpatient Study Investigators. N Engl J Med 1998;338:853-60.

44 Curtis JR, Yarnold PR, Schwartz DN, et al. Improvements in outcomes of acute respiratory failure for patients with human immunodeficiency virus-related Pneumocystis carinii pneumonia. Am J Respir Crit Care Med 2000;162:393-8.

45 Crothers K, Beard CB, Turner J, et al. Severity and outcome of HIV-associated Pneumocystis pneumonia containing Pneumocystis jirovecii dihydropteroate synthase gene mutations. AIDS 2005;19:801-5. 